\title{
The User Model, Vocabulary and Logical Architecture for Adaptive Augmented Reality
}

\author{
Maritzol Tenemaza \\ National Polytechnic School \\ Departament of Information \\ and Computer Science \\ Quito, Ecuador \\ maritzol.tenemaza@epn.edu.ec Madrid, España \\ Angélica de Antonio \\ Polythecnic University of \\ Madrid \\ Intelligent Virtual Environment \\ Laboratory \\ angelica@fi.upm.es
}

\author{
Jaime Ramírez \\ Polythecnic University of \\ Madrid \\ Intelligent Virtual Environment \\ Laboratory \\ Madrid, España \\ jramirez@fi.upm.es
}

\begin{abstract}
Adaptive Augmented Reality $\left(A^{2} R\right)$ is an emerging tech-nology that can support users in their daily life with useful information for their activities which is really adapted to the user's characteristics, to the environment where the activity is taking place, and to the current context. However, one of the problems identified is the lack of a formal definition of the models required and the logical architecture for the development of $A^{2} R$ systems. As a first step to this goal, our aim is to propose a detailed definition of the content of the User Model required for this type of systems. We explored state of the art ontologies for user modelling, and propose a set of significant user characteristics to be mod-elled. Also, we present an initial architectural model for this type of systems.
\end{abstract}

\section{INTRODUCTION}

Augmented Reality allows user to see the reality with overlaid digitally synthesized objects. Adaptive Augmented Reality $\left(A^{2} R\right)$ are augmented reality systems that respond to the user's interests and context with useful and effective realtime information.

The $A^{2} R$ needs to deal with fully mobile and dynamic environments, and at the same time these systems have to be able to adjust themselves to each user in the universe of people, for example, by selecting the most suitable multimodal presentation of the relevant information for each user.

The scope for adaptability in $A^{2} R$ systems is wider than in typical web systems. Taking into account that we will present our proposal of models for $A^{2} R$ and we will explain to what extent these models are covered by state of the art ontologies related to user modeling. We will focus on the user model and their characteristics. After that, we will present the architecture of a tourist guide app that will comprise the proposed models. This will serve to illustrate how these models can be arranged into an $A^{2} R$ application. As defining the models of this system, we will focus on especially in the user model by indicating which elements of UbisWorld ontology may be leveraged.
The structure of the remaining paper is as follows. In section 2, we will review the main ideas underlying adaptability in Web Systems. Then, in section 3 we will present our proposal of models for $A^{2} R$ systems. Later on, section 4 will examine some state of the art ontologies related to used modeling. Next, in section 5 we will present the tourist guide app and we will enumerate the main elements of its user model. Section 6 will sketch the architecture of the tourist guide app and will explain the role of each model in the whole. In addition, this section will pose some scenarios of interaction that will illustrate how the adaptability of the tourist guide app. Finally, we will conclude with some conclusions and some possible future lines of research.

\section{STATE OF THE ART - ADAPTABILITY IN WEB SYSTEMS}

The Google Glass software prototype appears to be a fullblown $A^{2} R$ application. However, the literature on $A^{2} R$ have not reported yet an analysis of necessary models and their representative features, furthermore not presented a possible architecture necessary for developing these systems. On the other hand, adaptability has been successfully implemented in web applications. For this reason, we are impelled to begin our research both with hypermedia and web applications.

\subsection{Adaptability Models}

The first generation of adaptable systems were hypermedia systems or pre-web systems; these systems adapted the 
presentation and navigation for a closed corpus system. The second generation was born to deal with huge quantities of information available on Internet, these ones were named web systems, and they adapted the content considering not only a user's knowledge but also the user interest as well. The third generation were mobile systems; these systems not only adapted to the user but also to the user's context [9].

For Heufemann [9] the models proposed for web system are:

- User Model: the user is represented in terms of his/her personal characteristics, preferences and behavior. The behavior is represented as the interaction and the context of user. The user model describes the user from the system's point of view and defines the goal of the adaptation.

- Domain Model: the actual representation varies depending on the application domain and the goal to be supported by each Web system.

- Adaptation Model: specifies how the different elements (Domain Model) are going to be organized given an specific user (User Model).

As shown above, the user model contains implicitly two models that influence in its behavior, the context model and interaction model. We think that these models should be independent.

This division into models promotes a better understanding of the adaptation process. Below we will identify the different characteristics of users that are useful and relevant for adapting applications to their interests and needs.

\subsection{User Characteristics Relevant to Adapta- tion}

\subsubsection{Features of the User relevant to Adaptation}

The most popular and useful features for user models are the following ones: User knowledge, interests, objectives, background, and individual traits [3]. Below we will review them one by one.

\section{User Knowledge}

User knowledge is very important and depends upon the application's domain [11] [10]. Yet it is variable in nature. The user can both acquire new knowledge and forget things. This can happen in the interim between sessions. An adaptive application based on user knowledge has to be able to recognize changes in the state of the user's knowledge, and thus update the user model.

\section{Interests}

Interests are useful criteria for data recovery and filtering in adaptive applications that manage large volumes of data [2] [10].

\section{Objectives and Tasks}

In the near term, users are interested in fulfilling objectives and completing tasks. Depending on the application, users may have an immediate need to access data (data access systems), or are participating in a training program (educational systems). User objectives are highly subject to change. Objectives may change between consecutive periods of accessing the application, or while using the application during the same session.

\section{Background}

The user's background contains a set of characteristics related to her or his prior experiences, often including professional information, responsibilities, and her or his work experience in related areas.

Background information is often used to adapt content in adaptive searches and to support navigation.

By its nature, the user's background doesn't change while they are accessing the application. However, it is not possible to deduce it simply by observing. Rather, the user must explicitly deliver that information.

\section{Individual Characteristics}

They are the characteristics that, taken together, define a person as an individual. For example, they include aspects of the personality (introverted/extroverted), cognitive styles (holistic/serial thinker), cognitive factors (capacity to memorize) and learning styles [2].

Similar to the user's background, individual characteristics are generally stable. Either they never change or they may change after a long period of time. However, unlike background, individual traits cannot be extracted simply by interviewing the user, but one must design rigorous psychological tests to discover them. Many researchers agree that it is important to model individual characteristics and use them in adaptive applications [2].

\section{Emotional state}

Brusilovsky-Millan [3] finds the concept of emotional state useful for capturing data about user motivation, frustration or commitment. Applications can capture data from user interactions or sensors to find out the emotional state of the user. In contrast to individual characteristics, emotional state is temporary and variable.

\subsection{Adaptation Types}

Adaptation of content, presentation and navigation concentrates on the user model. As we have seen, the user model represents the user's preferences, interests, user knowledge, objectives, etc. At the same time, these can change between logins or even during the same login session. Changes manifest themselves as the user interacts with the system through navigation choices, Internet searches, and interaction with social networks. Changes can also be recognized in a specific context by identifying restrictions and representations.

The different types of adaptation are:

- Content Adaptation. In adaptation of content, the data delivered are modified with the goal of fulfilling an access requirement [9] [4] . Customization of content means presenting different data for different users. The data presented should be only that which is useful to the user, depending upon their preferences. 
- Adapting the presentation. Once the most relevant content is selected and has been structured according to the context under which the user is interacting, the content is organized so that it is adequately shown to each user [9] [4].

- Adapting Navigation. Once we identify the users' needs, objectives, interests, and user knowledge and capture them in the user model [1], we can tackle the adaptation of navigation. A website's linkage structure can be modified to facilitate data searches. The idea is to dynamically generate shorter search paths that provide the required data [9]. In other words, we should select the links most relevant to the user, changing the original navigation framework in order to reduce web page relationships.

\section{PROPOSED MODELS FOR $A^{2} R$}

In this section we will present our proposal of models for $A^{2} R$. This proposal extends previous works in web applications with information that becomes relevant when considering $A^{2} R$ systems. Thus, we propose the set of models presented in Figure 1.

Here is a description of each model proposed:

- User model. In terms of the personal and cognitive data represented, the user model is similar to that of web systems. However, the user model in $A^{2} R$ goes far beyond, because the user's physical and physiological features and behaviour must also be taken into account and analysed in real-time. Data such as the stride length of the user, his/her state of health, and other important characteristics are used for $A^{2} R$ analysis. The model must receive input data both prior to interaction and during user's engagement with the system. Therefore, it is necessary to define rules for updating the model accordingly.

- Context model. This model represents a snapshot taken from the situation in which a user is using the system in a particular environment in a particular way. It is different from a traditional context model because it takes into account the real environment.

- Interaction model. This model represents the evolution of the user-system-environment interaction. What distinguishes it from context is that context is an instant snapshot, while the interaction model registers the history of interactions and the evolution in the context. It serves as a data source for enriching the users model.

- Environment model. This model represents attributes of objects, persons, locations, and all other aspects related to the real physical environment in which the user uses the system.

- Adaptation model. According to [9], the system should adapt content, navigation and presentation. Based on this requirement, the proposed model defines how to adapt output data coming from the content model taking into account interests and other user's characteristics represented in the user model. Moreover, it will consider defined restrictions in the environmental model and, if necessary, data from the interaction model. Also, the adaptation should take into consideration the current context. The resulting information should be presented in a user-friendly, multimodal form, without forgetting the importance of the humancomputer interface, both for mobile phones and other $A^{2} R$ devices.

\section{ONTOLOGIES APPLIED TO MODELS FOR} $A^{2} R$

An ontology is a computational model that describes a conceptualization of the world [5].

Ontologies become important in $A^{2} R$ because they can provide a formal vocabulary for specifying $A^{2} R$ models.

To the best of our knowledge there is only one work [8] that proposes ontologies to formalize $A^{2} R$ models and rules to update them. It defines several $A^{2} R$ applications that utilize ontologies:

- Search for a defined resource in a defined area within the user's environment. For example, in an office in which there are several printers, the user would define an area and the system would identify which locations have available printers in that area. The system would use a distance criterium between the user and instantiated printers to determine which printers to display.

- Retrieval of relevant documents from a library or archive. The context model helps to determine which documents should be displayed, based on the user's interests.

- A third application would display human-assisted virtual environments for senior citizens who live alone, in cases in which they request help for daily activities, increasing their quality of life and helping them maintain their autonomy.

All of these applications require an ontological model, described in the OWL language, which comprises the following four ontologies:

- User ontology: this refers to a user model in which the user's personal characteristics are represented, what the user wants to do and what she or he is doing, as well as social connections.

- Device ontology: This is a formal description of the pertinent devices and their characteristics.

- Physical environment ontology: including spatial distribution, object models and their physical relationships.

- Service ontology: this specifies the contextual model of specified applications and services that users can access. These have an AR interface.

This work concludes that ontologies together with reasoning techniques allow the $A^{2} R$ systems to:

- Reduce ambiguity in contextual data in order to improve data quality.

- Determine what data should be displayed to the user by evaluating explicit data about the user's situation and preferences. 


\begin{tabular}{l} 
System Environ- \\
ment with respect \\
of the user \\
- Other interesting \\
devices. \\
- Spatial - temporal \\
(reality, names of \\
streets, maps, \\
temperature, weather,) \\
- Environment( \\
environment surround, \\
luminosity, address \\
objects or QR code \\
and others codes, \\
camera image) \\
- Other interesting \\
people (distance) \\
- Other interesting \\
objects (for \\
reconnaissance of \\
places) \\
- Social Networking \\
(interesting \\
information). \\
- Other web sites \\
(interesting \\
information). \\
- Other software \\
(security, parallel \\
analysis ) \\
- Object Access rules. \\
\hline
\end{tabular}

System Environnt with respect

- Other interesting reality, names of temperature, weather.)

- Environment( environment surround, luminosity, address and others codes, camera image

- Other interesting places)

- Social Networking

- Other web sites information

- Other software analysis

- Object Access rules
System Data

- Content dependent on the type of system. (ontological representation)

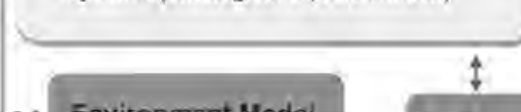

Environment Modei
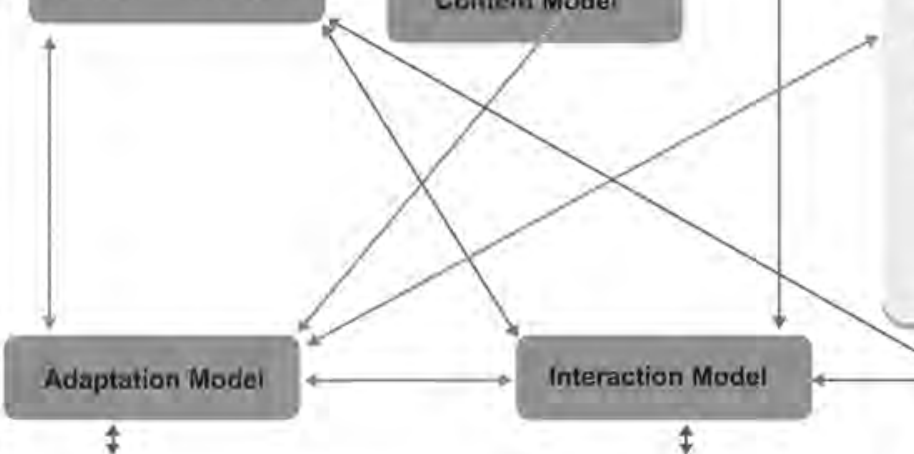

$\uparrow$

Adaptation of data presentation

Multimodal

presentation of

useful information

tailored to the needs

of each user.

Adaptation

Mechanisms

Adaptation rules for data.

Historical User interaction
User interaction with the environment (Iongitude,
latitude, marks interest objects, eye direction,
voice commands)
User interaction with the devices (sensors,
authorization, diary, dialed numbers, accessed
sites, safe data, state staff).
User interaction with the system (important data,
models)
Device interaction with the environment (location
(GPS), objects brands)

- Static

- Personal Data

o Objectives and Tasks.

- Variable

o Physical

- Disabilities Path length, Body position Individual Traits, among other

- Physiological: breathing, hearing, blood circulation, among other

- Cognitive

- Knowledge

Interests

- Preferences

- Background

- Cognitive and learning styles

- Affective state

Context Model

\section{$\downarrow$}

Playing a snapshot of user activity on the environment and system

Context of use of the device (what information used, how you use it) Sensory context (look, voice, movement) Spatial Temporal Context (Iocation, distance, speed, movement pattern)

Use System context (how to use the data and collecting information system)

Personal Context (pressure, heartbeat, fingerprint)

Networking context (Data of social web) (depends on the problem to be solved)

Figure 1: Features for each $A^{2} R$ Model

- Infer anticipated data using reasoning techniques.

Our set of proposed models extend and re-structure this proposal with new ontologies that were not considered, such as the Interaction Model, the Adaptation Model or the Content Model, and witl a more fine-grained structure in which the data about the current situation of the user is segregated into the Context Model.

\subsection{Analysis of external relevant ontologies}

Even if the use of ontologies in $A^{2} R$ systems is quite recent. some ontological models of users and environments have been previously developed in the context of adaptive and ubiquitous systems. It is the aim of this work to describe the most relevant existing ontologies that have been found and to compare them with the requirements imposed by our definition of $A^{2} R$ models, in order to determine their suitability and coverage.

- GUMO (General User Model Ontology): Expressed in the OWL language, GUMO supports the representation of user models. In this ontology the information is modelled in terms of user model dimensions. A user model dimension is divided into three parts: Auxiliary, Predicate and range [7], e.g the user's low interest in football would be represented by the Auxiliary "has interest". the Predicate "football" and the Range "low"
[6]. After its creation. this ontology was included into the UbisWord Ontology (ses below).

- SUMO (Suggested Upper Merged Ontology) ${ }^{1}$ : SUMO is the only formal ontology that has been mapped to all of the WordNet lexicon. SUMO is written in SUO-KIF language, but a translation to OWL is available. It is free and owned by the IEEE ${ }^{2}$. Part of this ontology has also been included into the UbisWorld Ontology.

- Ubisworld ${ }^{3}$ : It is an ontology for Web 2.0. It represents parts of the real world, like an office, a shop, a museum, an airport or a city. It represents persons, objects, locatious as well as time events and their properties and features. It is available in OWL. The knowledge about concepts, individuals and relations in UbisWorld is modelled by means of two ontologies: GUMO and the Ubis Ontology 4 .

\section{DESIGN DECISIONS FOR THE USER MO- DEL}

\footnotetext{
${ }^{1}$ http://www.adampease.org/OP/

${ }^{2}$ http://www.adampease.org/OP/

${ }^{3}$ http://www.ubisworld.org/

${ }^{4}$ http://ubisworld.org/index.php
} 
Considering as a starting point that "A user Model is a knowledge source in a system which contains explicit asumptions on all aspects of the user that may be relevant to the behavior of the system. These asumptions must be separable by the system from the rest of the system knowledge" [6], we decided to focus our analysis on a concrete prototype system to function as a tourist guide in the historical center of the city of Quito in Ecuador. Even if there are already many tourist guide systems, we considered this application area as an excellent testbed to evaluate the contribution of adaptability in Augmented Reality.

In the table 1 we present fundamental aspects to be considered about the user with the objective to identify the relevant characteristics and relationships for the proposed system. We incorporate aspects related to the source of data in a mobile environment for an ubiquitous system.

We show what we have considered to be the principal characteristics for the tourist guide system of Quito. Other characteristics that might be relevant but are less significant for adaptation or more difficult to capture or infer, such as personality, facial expression, emotional state, physical state, or physiological records, will be considered in future prototypes.

Given that Ubisworld is the most complete ontology found for ubiquitous systems, we thought that it would be worth checking to which extent Ubisworld already covers the needs of $A^{2} R$. To this end, in table 1 we also show how Ubisworld models the different types of information required.

Apparently, the table 1 shows that Ubisworld provides a quite good coverage of the needs of $A^{2} R$, although with some significant gaps, such as the lack of support for the representation of the user's sensorial context (what the user is looking at, hearing or touching), and the lack of proper constructs for the representation of the Interaction Model.

However, in the table 1, we show the principal characteristics to be considered for the system of tourist guide in Quito. But other characteristics such: personality, facial expressed, emotional, mental, psychological, physical and physiological are very important but not were represented because the only objective of the system is demonstrate the utility of the process of adaptability therefore they aren't necessary in this moment.

\section{ARCHITECTURE FOR THE TOURIST GUIDE APP}

Tour guide app will make recommendations for interesting sites taking into account which sites were visited by other people who were in the same place. This makes sense in places where there are many sites of interest, and typically there is not enough time to visit all of them. We will apply collaborative filtering to achieve this objective.

To infer interest on something, we will use the GPS, the compass and image recognition. So, if it is detected that the user is stopped for a while in front of a site of interest and he/she is looking at that site through the augmented reality device (providing a layer of information on that site), then the system will register interest on that site in the user model. In addition, if the user asks for further information on that site, this reinforces the interest on that site.

According to the features of this app, we can envision the architecture sketched in Figure 2, in which we can distinguish the following six layers:
- "The data layer", which contains most of the $A^{2} R$ models of our proposal, will serve to keep a local repository of the information relevant for the adaptation. The sources of data for this layer will be the own device and the cloud (social networks, user activity in the Web, etc.). More concretely, this layer will comprise the following models:

- User model: there are two types of information in the user model. Static information with invariant characteristics of the user such as: contact information, demographics, abilities, relationships and role. And dynamic information, which contains variable characteristics of the user such as: preferences, interests and knowledge, as well as motion and Objective and tasks. This model is updated by inferring user's interests and preferences from information included in the context, interaction and environment models. The user model will be essential for inferring the most relevant contents to the user. The user model is specific for each person.

- Environment model: this model will represent the structure of the streets and squares of the center of Quito as well as the locations of the different interesting places for sightseeing. In real time, the environment of each user is unpredictable, because the user moves across different streets. However, we will assume that the interesting places that can be visited remain in the same place. In the near future the Internet of things will eliminate this model.

- Context model: this model will contain the information provided by device sensors. More precisely, this model will be fed with information coming from the GPS, the encompass, the image recognizer, the touch screen, etc.

- Interaction model: this model will encompasses the route followed and the interesting places visited by the user so far as well as the user's interaction with the device along this route. This information will be very valuable for collaborative filtering and therefore it will be employed to suggest interesting places and routes to other users.

- Content model: this model will contain useful and engaging descriptions of each interesting place for sightseeing.

- "The Service Layer" will comprise mainly algorithms and rules to support the three types of adaptation. To this end, adaptation model will consider information provided by the device, the user model, the content model and the user models of other users that visited the same area (collaborative filtering).

- "Device Layer" represents the device as a source of data for the models.

- "Cloud Layer" is another splendid data source, because it can provide the user's fingerprint in the Web including his/her activity in social networks or his/her navigation behavior. 
Table 1: Mapping from $A^{2} R$ models to UbisWorld ontologies

\begin{tabular}{|c|c|c|c|c|c|}
\hline $\begin{array}{l}\text { User } \\
\text { Model }\end{array}$ & Characteristics & Source of Data & $\begin{array}{c}\text { Characteristics useful of } \\
\text { external ontologies } \\
\text { (Ubisworld) }\end{array}$ & Application & $\begin{array}{l}\text { Type of } \\
\text { data }\end{array}$ \\
\hline \multirow[t]{5}{*}{$\begin{array}{l}\text { Static } \\
\text { Per- } \\
\text { sonal } \\
\text { Data }\end{array}$} & $\begin{array}{l}\text { Contact Infor- } \\
\text { mation }\end{array}$ & $\begin{array}{l}\text { Device or social } \\
\text { networks or the } \\
\text { user profile. }\end{array}$ & $\begin{array}{l}\text { Given name, Family name, } \\
\text { Street, House number, Postal } \\
\text { code, city, state, country, tele- } \\
\text { phone number, mobile phone, } \\
\text { email. }\end{array}$ & $\begin{array}{l}\text { The system can use the } \\
\text { name for naming to } \\
\text { the user. For helping } \\
\text { through voice message } \\
\text { or in the other situa- } \\
\text { tions. }\end{array}$ & $\begin{array}{l}\text { Static In } \\
\text { the time } \\
\text { and the } \\
\text { space. }\end{array}$ \\
\hline & Demographics & $\begin{array}{ll}\text { Social Network, } \\
\text { device, or User } \\
\text { profile. }\end{array}$ & $\begin{array}{l}\text { Birthday, Birthplace, Educa- } \\
\text { tional level, First language, } \\
\text { Second language, Sex. }\end{array}$ & $\begin{array}{l}\text { The system can use the } \\
\text { name for naming to } \\
\text { the user. For helping } \\
\text { through voice message } \\
\text { or in the other situa- } \\
\text { tions. Identify interests } \\
\text { according to level of ed- } \\
\text { ucation } \\
\text { The first language will } \\
\text { be used for display of } \\
\text { results or for present in- } \\
\text { formation by voice. } \\
\text { Identify interests ac- } \\
\text { cording to sex. }\end{array}$ & $\begin{array}{l}\text { Static } \\
\text { informa- } \\
\text { tion }\end{array}$ \\
\hline & Abilities & $\begin{array}{l}\text { User Profile. } \\
\text { Ability to see, } \\
\text { ability to hear, } \\
\text { ability to walk, } \\
\text { ability to cycle, } \\
\text { ability to talk. }\end{array}$ & $\begin{array}{l}\text { For adapting information.(to } \\
\text { see, to hear, to talk) }\end{array}$ & $\begin{array}{l}\text { For help to the user (to } \\
\text { cycle, to walk) }\end{array}$ & $\begin{array}{l}\text { They are } \\
\text { acquired } \\
\text { skills, } \\
\text { thus are } \\
\text { static, in } \\
\text { the time. }\end{array}$ \\
\hline & Relationships & $\begin{array}{lr}\text { Social } & \text { networks, } \\
\text { device, } & \text { user } \\
\text { profile. } & \\
\end{array}$ & $\begin{array}{l}\text { Friend, Colleague, Family, } \\
\text { Other }\end{array}$ & $\begin{array}{l}\text { Identify groups people } \\
\text { related with the user } \\
\text { for identify common in- } \\
\text { terests. }\end{array}$ & $\begin{array}{l}\text { Static } \\
\text { informa- } \\
\text { tion }\end{array}$ \\
\hline & Role & $\begin{array}{l}\text { User profile, so- } \\
\text { cial Networks. }\end{array}$ & $\begin{array}{l}\text { Tourist, businessman, em- } \\
\text { ployee, manager, learner, } \\
\text { teacher, child, parent, cus- } \\
\text { tomer, salesman, user, devel- } \\
\text { oper, author, reader, producer, } \\
\text { consumer, inhabitant. }\end{array}$ & $\begin{array}{l}\text { Very important to de- } \\
\text { fine the type of infor- } \\
\text { mation to be presented } \\
\text { to the user. }\end{array}$ & $\begin{array}{l}\text { Static in } \\
\text { the time. }\end{array}$ \\
\hline $\begin{array}{l}\text { Variable } \\
\text { Per- } \\
\text { sonal } \\
\text { Data }\end{array}$ & Motion & $\begin{array}{l}\text { Camera (going to } \\
\text { stairs, going down } \\
\text { stairs) Sensors of } \\
\text { device (walking) }\end{array}$ & $\begin{array}{l}\text { Walking, sitting, lying, stand- } \\
\text { ing going up stairs, going down } \\
\text { stairs }\end{array}$ & $\begin{array}{l}\text { These options will be } \\
\text { used for identifying the } \\
\text { position of user for } \\
\text { defining of interest of } \\
\text { user }\end{array}$ & $\begin{array}{l}\text { Variable } \\
\text { in inten- } \\
\text { sity and } \\
\text { time }\end{array}$ \\
\hline $\begin{array}{l}\text { Objective } \\
\text { tasks }\end{array}$ & $\begin{array}{l}\text { Objective } \\
\text { tasks }\end{array}$ & $\begin{array}{l}\text { Device, user pro- } \\
\text { file, analyzing } \\
\text { their role }\end{array}$ & $\begin{array}{l}\text { hasTask, hasPlan, hasGoal, } \\
\text { hasDone, has experience }\end{array}$ & $\begin{array}{l}\text { It is utile for identify } \\
\text { user's interests }\end{array}$ & $\begin{array}{l}\text { Can be } \\
\text { Static or } \\
\text { variable }\end{array}$ \\
\hline Cognitive & $\begin{array}{l}\text { Knowledge, in- } \\
\text { terests, prefer- } \\
\text { ences }\end{array}$ & User profile. & 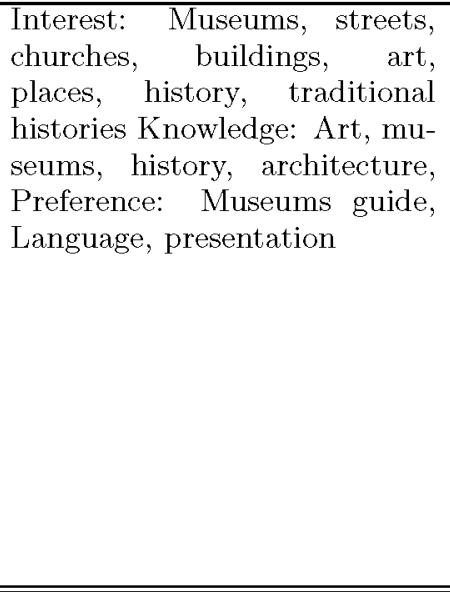 & $\begin{array}{l}\text { It will be used for } \\
\text { adaptation of con- } \\
\text { tent, presentation, } \\
\text { or navigation Inter- } \\
\text { ests preferences differ } \\
\text { therefore preferences } \\
\text { complement interest. } \\
\text { For example if the } \\
\text { user's interest is on } \\
\text { particular type of food, } \\
\text { for example national } \\
\text { food but may prefer a } \\
\text { certain type of restau- } \\
\text { rants, within that line } \\
\text { of restaurants (cheap, } \\
\text { average or expensive) }\end{array}$ & $\begin{array}{l}\text { Static or } \\
\text { Variable }\end{array}$ \\
\hline
\end{tabular}




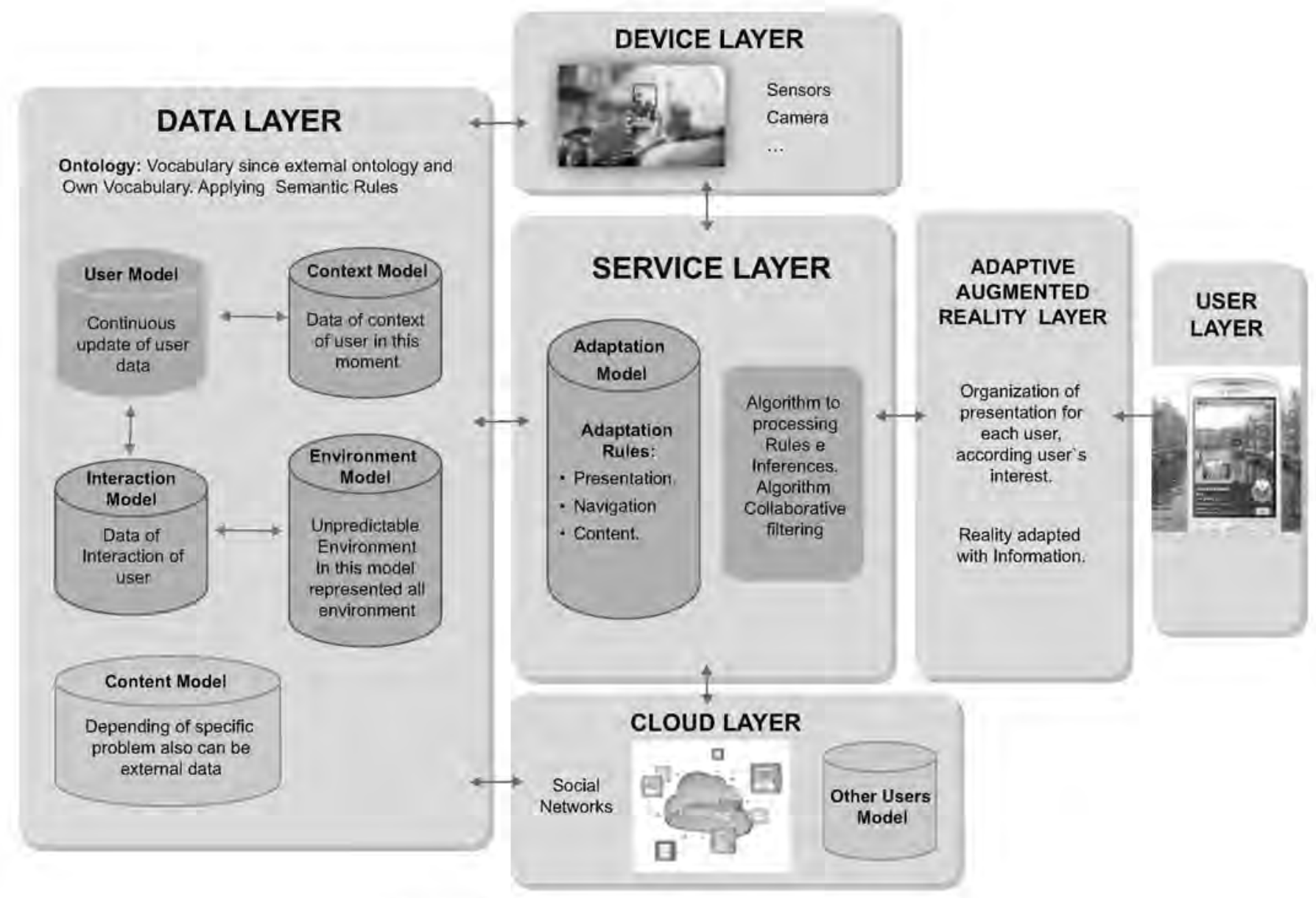

Figure 2: Architecture for tourist guide app

- "Adaptive Augmented Reality Layer" represents the augmented reality interface with the user. In this app, real objects captured by the camera will be labeled with textual information on the screen and/or voice comments will be provided on the interesting places in the close environment of the user.

- "User Layer" represents the user as a target of the system.

\section{SCENARIOS OF INTERACTION OF SYS- TEM}

We present two possible situations of interaction that illustrate the utility of Adaptability in Augmented Reality systerns.

Quito has the best preserved historical center in Latin America, and particularly there are many churches. While a person is visiting a specific church, the system should realize the current location of the user and decide not to disturb with audio messages, but instead use visual output to transmit relevant information. The system can provide the user with information relative to the artworks in front of which he stands, and with history of the church, because the system knows about the user's interest in history. Knowing that the user has previously visited another church which was built during the same historical period, the system could also highlight the commonalities and differences between them. Moreover, as a close friend of the user also visited this same church last year, the system could suggest the user to pay more attention to a piece of artwork that was particularly well valued by him, In order for this scenario to become feasible, the system should determine: a) the coordinates where the user is at this moment, and the fact that the user is currently standing (Context Model) b) the correspondence between those coordinates and a particular place, the church, and a particular object, the object of attention of the user at this moment, the artwork (Environment Model), c) relevant information about the current place and the object of interest (Content Model), d) the relevant knowledge and interests of the user, particularly History (User Model), e) the previous history of interaction between the user and the environment, particularly other churches that were previously visited by him (Interaction Model), f) people in the user's social network that might be related to this place (Other users' Interaction Model). Considering all this information, the adaptation rules would decide about the appropriate information to present (only historical information, filtering out architectural information which is not interesting for this user), and the appropriate way to present it (visually, and not auditory). This adaptation, as it can be appreciated, would rely on the different models presented in figure 2 . 


\section{CONCLUSION}

Adaptive Web systems are examples of successful application of adaptability, both to users' interests and to their real-time context. Although some efforts have been made to develop Adaptive Augmented Reality, this technology has not yet equaled the adaptability levels achieved by web systems.

One of the reasons for this primitive state in adaptability might be that the development of a $A^{2} R$ is still a very complex endeavour, encompassing many technological challenges, without clear and specific process models and methodological and architectural guidelines to lead the development process, and with still too simple development tools.

We aim at the definition of an architectural model for $A^{2} R$ systems, which is structured around a basic set of models for $A^{2} R$ applications, which are inspired in models coming from adaptive web systems. As part of this work, we have sketched the architecture of a prototype, the tourist guide for the historic center of Quito, that eventually allows us to validate the suitability of the proposed models. As designing this app, we will use ontologies to represent the relevant information; rules for updating some models; and collaborative filtering for inferring probable interests.

To the best our knowledge, there is just one work that addresses the development of $A^{2} R$ models by using ontologies and rules. This work manages to demonstrate that rules represent a good approach to define the adaptation model and to update $A^{2} R$ models formalized with ontologies. On the other hand, we think that there is still much work to be done regarding alternative approaches to define the adaptation model and the update mechanisms associated to the models.

\section{FUTURE WORK}

Based on our conclusions, we have identified the following future lines of research for $A^{2} R$ technology:

1. Formalize the models using ontologies in widely accepted languages like $O W L$ and applying knowledge engineering good practices.

2. Define the means for initializing and updating the models. Identify data sources within the environment and context.

3. Specify how the adaptation model selects content to be presented to the user. To develop customized adaptations in real-time, we need to:

- Research and define potential components of the adaptation model that recognize changes in interest, starting from the user and context models and taking into account the environment and user interactions.

- Investigate how the adaptation model proposes new content by drawing on data from the content model, recognizing changes in the environment and interests from the user model, and interpreting the real-time context and user interactions with it.

- Define how the adaptation model defines the content presentation mode through its multimodal interface. The model should take into consideration the specifics of each device and the user's preferences.
4. Evaluate how the context model interprets user activities, so that data are validated at the instant when the data are adapted in real-time.

5. Undertake a comprehensive evaluation of both the models and their attributes and the level of adaptability achieved. The goal is to identify and assess the advantages and benefits delivered at the moment when the user interacts with both specific and general contexts within the $A^{2} R$ system.

6. Define a formal, systematic, and general process for the analysis and design of $A^{2} R$ systems. These systems can then be customized to solve specific problems. Essential guidelines for adaptation and evaluation must be included, so that prior contributions add to the systematized design of the $A^{2} R$ system.

7. Complete the implementation of the tourist guide app and other prototypes that allow us to check the suitability of the proposed architecture and models.

\section{REFERENCES}

[1] P. Brusilovsky. Methods and techniques of adaptive hypermedia. User modeling and user-adapted interaction, 6(2-3):87-129, 1996.

[2] P. Brusilovsky. User modeling and user-adapted interaction. In Adaptive Hypermedia, volume 11, pages $87-110,2001$.

[3] P. Brusilovsky and E. Millán. User models for adaptive hypermedia and adaptive educational systems. In The adaptive web, pages 3-53. Springer-Verlag, 2007.

[4] A. Bunt, G. Carenini, and C. Conati. Adaptive content presentation for the web. In The adaptive web, pages 409-432. Springer, 2007.

[5] A. U. Frank. Ontology for spatio-temporal databases. Springer, 2003.

[6] D. Heckmann. Ubiquitous user modeling, volume 297. IOS Press, 2006.

[7] D. Heckmann, T. Schwartz, B. Brandherm, M. Schmitz, and M. von Wilamowitz-Moellendorff. Gumo-the general user model ontology. In User modeling 2005, pages 428-432. Springer, 2005.

[8] R. Hervás, J. Bravo, J. Fontecha, and V. Villarreal. Achieving adaptive augmented reality through ontological context-awareness applied to aal scenarios. J. UCS, 19(9):1334-1349, 2013.

[9] P. L. Heufemann, J. G. Villegas, and I.-Y. Ko. Web usage based adaptive systems. In Advanced Techniques in Web Intelligence-2, pages 127-148. Springer, 2013.

[10] A. Kobsa. Generic user modeling systems. User modeling and user-adapted interaction, 11(1-2):49-63, 2001.

[11] A. C. Martins, L. Faria, C. V. De Carvalho, and E. Carrapatoso. User modeling in adaptive hypermedia educational systems. Journal of Educational Technology \& Society, 11(1):194-207, 2008. 